\title{
Of risks and regulations: how leading U.S. nanoscientists form policy stances about nanotechnology
}

\author{
Elizabeth A. Corley · Dietram A. Scheufele • \\ Qian Hu
}

Received: 2 March 2009/Accepted: 29 May 2009/Published online: 17 June 2009

(C) Springer Science+Business Media B.V. 2009

\begin{abstract}
Even though there is a high degree of scientific uncertainty about the risks of nanotechnology, many scholars have argued that policy-making cannot be placed on hold until risk assessments are complete (Faunce, Med J Aust 186(4):189-191, 2007; Kuzma, J Nanopart Res 9(1):165-182, 2007; O’Brien and Cummins, Hum Ecol Risk Assess 14(3):568-592, 2008; Powell et al., Environ Manag 42(3):426-443, 2008). In the absence of risk assessment data, decision makers often rely on scientists' input about risks and regulation to make policy decisions. The research we present here goes beyond the earlier descriptive studies about nanotechnology regulation to explore the heuristics that the leading U.S. nanoscientists use when they make policy decisions about regulating nanotechnology. In particular, we explore the relationship between nanoscientists' risk and benefit perceptions and their support for nanotech regulation. We conclude that nanoscientists are more supportive of regulating nanotechnology when they perceive higher levels of risks; yet, their perceived benefits about
\end{abstract}

E. A. Corley $(\bowtie) \cdot$ Q. Hu

School of Public Affairs, Arizona State University, 411 N. Central Avenue, Suite 450, Phoenix, AZ 85004, USA

e-mail: elizabeth.corley@asu.edu

D. A. Scheufele

Department of Life Sciences Communication, University of Wisconsin, 1545 Observatory Drive, Madison, WI 53706, USA nanotechnology do not significantly impact their support for nanotech regulation. We also find some gender and disciplinary differences among the nanoscientists. Males are less supportive of nanotech regulation than their female peers and materials scientists are more supportive of nanotechnology regulation than scientists in other fields. Lastly, our findings illustrate that the leading U.S. nanoscientists see the areas of surveillance/privacy, human enhancement, medicine, and environment as the nanotech application areas that are most in need of new regulations.

Keywords Risks - Benefits - Regulations · Policy $\cdot$ Scientists $\cdot$ Survey $\cdot$ Nanoscale science and engineering · ELSI

Some scholars have argued that nanotechnology is the defining technology of the twenty-first century (Besley et al. 2008; Bowman and Hodge 2006; Chau et al. 2007; Renn and Roco 2006). Regardless of whether this statement will be true over the long term, there is no denying that the use of nanotechnology has infiltrated a variety of products and commercial applications within the fields of biotechnology, electronics, and healthcare, among others. Even though technology transfer appears to be alive and well within the field of nanotech, policy discussions about the social, political, and ethical implications remain 
limited (Bennett and Sarewitz 2006; Bowman and Hodge 2006; Fisher 2007; Scheufele et al. 2007). Only recently have social scientists and policy-makers started to pay attention to the social dimensions of nanotechnology research, particularly within the context of how we might regulate it (Besley et al. 2008; Cobb and Macoubrie 2004; Friedman and Egolf 2005; Gewin 2006; Scheufele and Lewenstein 2005; Schummer and Baird 2006). In addition, most previous studies that have focused on the regulation of nanotechnology have used descriptive analyses or have tended to focus on normative suggestions for adapting or reforming the existing regulation system (Renn and Roco 2006).

The research presented here goes beyond the earlier descriptive studies about nanotechnology regulation to explore the way leading U.S. nanoscientists make policy decisions about regulating nanotechnology. Some scholars have explored mental shortcuts and heuristics among scientists (Magnus 1997; Samarapungavan, Westby and Bodner 2006) and how they can lead to perceptual biases about regulation (Sunstein 2005). This literature, however, is sparse, and no studies - to our knowledge-have explored the heuristics that the leading U.S. nanoscientists use when they make policy decisions about the regulation of the field.

We, therefore, start our analysis by looking at similar studies that have been conducted for the U.S. public. Scheufele and Lewenstein (2005) found that in the face of incomplete information, the public relies on a series of heuristics to make decisions about nanotechnology. In particular, they found that the public tends to rely on perceptions of benefits, shaped by interpretive frames offered by mass media, when making these policy decisions (for an overview, see Scheufele (2006)). Along with the public, scientists are also members of the audience for different public discourses about emerging technologies. Iyengar (1991) showed that highly involved audiences are often highly attentive to relevant media outlets and therefore more susceptible to heuristics and other cues provided by these news sources. This includes cues provided by elite and mass media about how emerging technologies are being framed with respect to their risks and benefits. It could be argued, of course, that scientists have high levels of technical expertise about issues related to science and technology and are therefore less susceptible to potential media influences.
In the absence of scientific certainty, scholars have found that scientists often rely on heuristics or normative values in the same way that lay people do to make policy decisions (Carr and Levidow 2000; Frank 1988; Silva and Jenkins-Smith 2007; Sniderman et al. 1991; Zaller 1992). Thus, given the high level of scientific uncertainty about the current risks and benefits of nanotech (Chau et al. 2007; Friedrichs and Schulte 2007; Gewin 2006; Powell et al. 2008; Rickerby 2007), we expect that there are other heuristics that scientists use to make decisions about nanotechnology regulations. For example, we assume that nanoscientists have much higher levels of knowledge than the public about the risks and potential benefits of nanotechnology. Therefore, we expect that their expertise-based perceptions of risks and benefits will be the key factors that they will use to make decisions about the regulation of the field.

\section{Policy environment}

Having systematic and generalizable data about perceptions among nanoscientists is increasingly important, given the continued scarcity of conclusive data on the environmental and health risks related to nanomaterials (European Food Safety Authority 2009), and policy-making in this area cannot be placed on hold until risk assessments are complete (Faunce 2007; Kuzma 2007; O'Brien and Cummins 2008; Powell et al. 2008). While nanoscientists continue to move their research forward and learn more about the health and environmental risks of nanotechnology, policy-makers are trying to determine the best way to formulate new regulations under high levels of scientific uncertainty about the risks and benefits of the field. In this type of scientific, political, and regulatory environment, policy-makers often have to rely on scientists' perceptions about risks and benefits while they wait for the accumulation of policy-relevant risk assessment data. Since policy-makers do not yet have access to many quantitative (and validated) risk assessment studies for nanotechnology, the risk perceptions of nanoscientists will likely play an important role in developing short-term regulatory frameworks. After all, these scientists are probably more familiar with the risks and potential benefits of nanotechnology than anyone else because they work daily with nanomaterials in 
their labs and contribute to the nanotechnology research that is used to develop new commercial products.

Despite the difficulties of this policy environment, it is not a new situation for policy-makers. Nanotechnology is not the first emerging technology that has presented policy-makers with the task of developing regulations without high levels of scientific certainty about the risks and benefits of the technology. A similar regulatory environment occurred for climate change, genetically modified organisms (GMOs), and stem cell research-all technological areas where scientific uncertainty is relatively high. In these cases, we have also seen policy-makers rely on scientists' risk perceptions and judgments when risk assessment data were lacking. For example, Carr and Levidow (2000) have argued that in the case of GMOs, high levels of scientific uncertainty have led to policy decisions that have been based on scientists' professional judgment more than actual scientific evidence. As Silva and Jenkins-Smith (2007, p. 640) have argued "when policies concern risks and risk management, scientists may be called on to exercise judgment in extending less than certain scientific findings into policy recommendations (Jasanoff 1990; McGarity 1978-1979; Revkin 2004; Salter et al. 1988)."

Clearly, the high level of scientific uncertainty involved in evaluating the risks and benefits of nanotechnology has complicated the development and implementation of regulations both in the USA and internationally (Franco et al. 2007). In spite of these complications, policy-makers and regulatory agencies have started to make progress on developing policies that can protect the public from the risks of nanotechnology. As they continue to make new policies (and refine existing ones), they will continue to rely on scientists' judgments and opinions about both risk assessment and risk management. We conclude this article with some policy implications that will be useful for regulators and policy-makers, as they attempt to include scientists in their development of new regulatory frameworks for nanotechnology.

\section{Scientists' views on regulation}

Within the academic literature, there are several factors that might impact scientists' perceptions about the regulation of their field. In this section, we briefly discuss the factors that are most relevant for our study.

Regulation of nanotechnology

Even though the regulation of nanotechnology is a relatively new topic for the policy-making community, social science scholars are increasingly calling for the regulation of the field (Powell et al. 2008). Bowman and Hodge (2006) argued that there have been few debates about the social, ethical, and regulatory aspects of nanotechnology. They concluded that there is a regulatory gap between commercial applications and public expectations about regulatory protections for nanotechnology. In fact, some scholars are encouraging industry to take on a form of self-regulation until governmental regulations are in place, and this regulatory gap is closed (Lee and Jose 2008; Reinert et al. 2006).

The nature of nanotechnology makes it difficult for one agency to regulate all nano research and applications. Therefore, multiple federal agencies regulate products that may employ nanotechnology or nanomaterials, but there is no comprehensive regulatory framework. With this piecemeal approach, it is likely that certain technologies or products will not be fully regulated by any agency. Even though the FDA, for instance, typically regulates cosmetic products "the agency may have limited authority over the use of nanotechnology related to those products" (FDA 2009). In the case of cosmetics, there is "no premarket approval of cosmetic products or their ingredients, with the exception of color additives" (FDA 2009). There are potential risks associated with the use of nanomaterials in these types of products, however, and the FDA says that it is "currently not aware of any safety concerns," but is "planning additional studies to examine the effects of select nanoparticles on skin penetration" (FDA 2009). In the meantime, consumers continue to buy cosmetics and sunscreens that may contain nanomaterials without a clear indication of the potential risks and without a comprehensive regulatory framework in place. Yet, as Berube (2008) has argued, not all of these products pose unknown or high levels of risks for consumers. The larger problem in this example is that there is not a clear regulatory framework in place that provides consistent and comprehensive screening and protection for consumers. 
The above FDA case is one example of how the complexity of nanotechnology has challenged existing regulatory frameworks. Not only are current regulatory frameworks not designed to address nanotechnology research, but also the progress of risk assessment research in the field of nanotechnology is lagging behind the development of new products. Therefore, an additional issue facing scientists, the public, and policy-makers is how to regulate a technology that we know relatively little about in terms of potential human health and environmental impacts. These challenges are compounded by the fact that there is not much risk assessment data that can be used to develop nanotechnology regulation at this stage. Thus, the complexities of this policy case will require active involvement by the scientists that conduct research on nanomaterials. These are the scientists that we include in the survey results presented here and we explore the factors that they use to form policy stances about the regulation of nanotechnology.

Perceptions of risks and benefits

The weighing of risks and benefits of a new technology is a key component of making policy decisions. More restrictive regulations could limit potential benefits, and less restrictive regulations could expose the public to uncertain risks. Therefore, we expect the scientists in our sample to rely partly on their perceived risks and benefits of nanotechnology when making decisions about the regulation of the field. Previous research studies on both the public and nanoscientists have found that overall both groups have higher perceived benefits of nanotechnology than perceived risks (Besley et al. 2008; Cobb and Macoubrie 2004).

Yet, the potential risks (some known and many still unknown) associated with nanotechnology research and applications make the regulation of the field even more urgent. Echoing the emphasis on potential risks posed by nanotechnology, Besley et al. (2008) found that scientists' risk perceptions are closely related to their "perceived importance and adequacy of regulation." In particular, they argued that in the areas of human health and environment (where the perceived risk is highest), the perceived need for regulation was also quite strong.

Several scholars have compared the public's perception of nanotechnology risks and benefits with scientists' perspectives (Scheufele et al. 2007; Siegrist et al. 2007b). Siegrist et al. (2007b) found that scientists generally perceive less risk than lay people. Furthermore, they noted that the contributing factors to nanotechnology risk perceptions differ for these two groups. According to their research, while levels of trust, perceived benefits, and general attitudes toward technology affect lay people's perception of nanotechnology risk levels, knowledge and confidence in governmental agencies play more important roles in influencing nanoscientists' perception of nanotechnology risks. Some recent studies, however, have found that nanotechnology might be one of the first emerging technologies for which scientists are more concerned about some environmental and health risks than the public (Scheufele et al. 2007).

When conceptualizing the relationships between risks and the regulatory system, scholars have often differentiated between various levels of risks and regulation derived from diverse nanotechnology development and applications. For example, Renn and Roco (2006, p. 154) categorized the development of nanotechnology into four phases, evolving from "passive nanostructures," "active nanostructures," to "systems of nanosystems," and "molecular nanosystems." They noted that there should be different risk governance frames for different types of risks that originate from different stages of nanotechnology development. Here, we explore how scientists' risk and benefit perceptions about nanotechnology impact their support for the regulation of the field.

Social and economic values

Several studies have found that existing value frames impact people's support of regulation. Kunreuther and Slovic (1996) explored the complex societal values underlying risk assessment. Several other scholars have argued for placing the discussion of risk assessment and regulation of nanotechnology within a broader social context. Renn and Roco (2006) demonstrated that the governance of nanotechnology should be considered within a broader social context because rational "risk assessment" is not sufficient and should be accompanied by a "concern assessment" by experts, politicians, and the general public (Renn and Roco 2006, p. 169). The need for a "concern assessment" is particularly high when there are few rational risk assessment results 
available for policy-makers (as is the case for nanotechnology research right now). Since the assessment of risk for regulation is a social and cultural process, involving value choices, analytical tools, and measures accepted by the public (Kunreuther and Slovic 1996), we include a measure of political/social values in our models.

We also include measures of economic values in our models because nanotechnology is a field that has large potential for commercial applications and technology transfer. Economic values could be important considerations when we think about limiting economic opportunities with a regulatory framework. Some scholars have assumed that the failure to provide a comprehensive regulation system for nanotechnology results partly from the fact that nanotechnology has significant potential economic value, and therefore, policy-makers might be reluctant to let regulation stifle the development of commercial applications in the field (Bowman and Hodge 2006).

\section{Methodology}

\section{Data collection}

The data for this study came from the first nationally representative study of nanoscientists, and were collected between May and June 2007. The survey was conducted by mail and it focused on collecting data from 363 leading U.S. nanotechnology scientists and engineers. The survey was administered by the University of Wisconsin Survey Center in three waves following Dillman's Tailored Design Method (Dillman et al. 2008). The final response rate for the nanoscientist survey was 39.5\% (AAPOR RR-3: $39.5 \%$ ). The sampling design was based on identifying the first authors and contact authors for the most highly cited, recent nanotechnology publications that were indexed in the ISI Web of Knowledge database. In order to rigorously establish which publications were actually within the multidisciplinary field of nanotechnology, we drew on work by another group in the Center for Nanotechnology in Society at Arizona State University (CNS-ASU) that is tasked with refining the definition of nanotechnology using specific bibliometric terms. A detailed description of this group's refinement process for nanotechnology search terms is outlined in an article by Porter and colleagues (Porter et al. 2008).

In order to develop the final sample for the scientist survey, Porter and colleagues delivered to our team a database of 91,479 nanotechnology publications that were published between January 2005 and July 2006. We filtered these records to remove non-U.S.-affiliated scientists, graduate students, and first or contact authors who were cited less than five times in the publication database. This filtering process was used to ensure that the survey sample focused on the most highly cited, most active, U.S.-affiliated scientists within the nanotechnology field. The final filtering process produced 1,022 names, and this yielded 363 completed questionnaires.

As Table 1 illustrates, $86 \%$ of all the respondents were male, $46 \%$ had tenured academic positions, $6 \%$ worked in industry, $80 \%$ had current research supported by an individual government grant or contract, $27 \%$ had current research supported by a grant from industry, and $26 \%$ were supported by grants from both government and industry. This shows that almost all the researchers with industry support also relied on government grants.

The average age for the respondents was about 45 years and the average year for the receipt of a doctoral degree was 1991. We also observed some disciplinary diversity among the respondents. The largest percent of respondents were in the field of chemistry (38\%), followed by physics (22\%),

Table 1 Descriptive statistics $(N=363)$

\begin{tabular}{lr}
\hline & \multicolumn{1}{c}{ Mean } \\
\hline Demographic variables & \\
Age & 44.94 \\
Male (\%) & 85.59 \\
Career variables & 1991.21 \\
Year of PhD & 46.28 \\
Tenured (\%) & 80.17 \\
Supported by grants/contracts (\%) & \\
Field of PhD degree & 38.02 \\
Chemistry (\%) & 22.31 \\
Physics (\%) & 16.53 \\
Engineering (\%) & 9.64 \\
Materials science (\%) & 6.06 \\
Biology (\%) & 7.44 \\
Other (\%) & \\
\hline
\end{tabular}


engineering (17\%), materials sciences (10\%), and biology $(6 \%)$.

\section{Hypotheses}

Previous research has shown that scientists demonstrate higher levels of support for environmental regulation (Silva and Jenkins-Smith 2007) and nanotechnology regulation (Besley et al. 2008) when their risk perceptions are high. Here, we build on the previous research on nanotechnology regulation (Besley et al. 2008) by further testing this hypothesis with a multivariate analysis. We hypothesize that scientists with higher nanotechnology risk perceptions will support higher levels of nanotechnology regulation. In our analysis, we divide the perceived risks and benefits into particular application areas. Our decision to include these particular nanotechnology areas in our analysis is based on the previous research that has shown that perceptions about nanotechnology are dependent on the specific application of the technology (Kuzma et al. 2008; Siegrist et al. 2007a). Our second hypothesis is related to the relationship between scientists' perceived benefits and their support for regulation. We expect that as nanoscientists have higher perceptions about the benefits of nanotechnology, they will support lower levels of regulation to allow those benefits to be realized through academic and commercial research.

Our final hypothesis is related to scientists' values about the societal allocation of risk. Silva and Jenkins-Smith (2007) argued that for modeling regulation, it is important to include a control variable that captures scientists' perceptions about how risk in a society should be allocated and whether individual citizens should be exposed to risks if there are potentially large social gains as a result of the risks. In order to capture a measure of this societal allocation of risk, we included the following statement as a control variable in our analysis: "Advancing nanotechnology quickly is more important than protecting society from the unknown risks." ( $1=$ Strongly disagree; $5=$ Strongly agree $)$. Therefore, as scientists report higher ratings on this scale, they are more likely to think that it is acceptable for individuals in society to accept potential risks if the payoff is large for nanotechnology. Based on the findings by Silva and Jenkins-Smith (2007) on climate change and radiation protection, we hypothesize that higher levels of societal allocation of risk will be correlated with lower levels of support for regulation.

\section{Results}

Our first hypothesis was that scientists with higher risk perceptions would be more supportive of nanotechnology regulation. We tested this hypothesis in two ways using our dataset. The first way was by comparing the nanotechnology application areas where scientists had the highest risk perceptions with the areas where they believed that new regulations were needed. The results in the second half of Table 2 present the mean response for the scientists' risk perceptions across eight areas: overall risk, human health, privacy, terrorists, environmental, arms race, loss of jobs, and tiny robots. These results illustrate that the specific nanotechnology application areas for which scientists have the highest perceptions of risk are human health, privacy, terrorists, and the environment.

Next, we compared these areas of high risk perceptions with the areas that the scientists felt had insufficient nanotechnology regulations. In order to capture this, we asked the respondents to report whether they believed that "current regulations were sufficient" or "new regulations were needed" (on a 5-point Likert-type scale) for eight different areas of nanotechnology applications: cosmetics, military, medicine, bioengineering, environment, computers, privacy, and other consumer products. The participants' mean responses to these eight questions are presented in Table 3. Out of the eight areas of nanotechnology applications, the scientists believed that the four areas that most needed new regulations (i.e., for which current regulations were not sufficient) were privacy, human enhancement, the medical field, and the environment. Interestingly, these are also the areas for which the scientists had the highest risk perceptions. On the other hand, military/ defense and machines/computers were the two areas where the scientists were most likely to think that current regulations were sufficient.

We further tested this hypothesis (as well as our second and third hypotheses) using a multivariate analysis for the relationship between the support for regulation and risk perceptions, benefit perceptions 
Table 2 Summary statistics for regulation and risk/benefit perception variables

Response categories: $(1=$ Strongly disagree; $5=$ Strongly agree $)$

Mean SD

Regulation of nanotechnology

"Academic nanotechnology research should be regulated"

$2.12 \quad 1.22$

"Commercial nanotechnology research should be regulated"

Level of regulation of nanotechnology

"Regulations of nanotechnology should be implemented at the local level"

$2.04 \quad 1.17$

"Regulations of nanotechnology should be implemented at the national level"

"Regulations of nanotechnology should be implemented at the international level"

Risk perceptions

Loss of privacy: "Nanotech may lead to the loss of personal privacy because of tiny new surveillance devices" $2.81 \quad 1.21$

Lead to arms race: "Nanotech may lead to an arms race between the U.S. and other countries" $2.27 \quad 1.16$

Used by terrorists: "Nanotech may be used by terrorists against the U.S." $2.69 \quad 1.21$

Lead to human health problems: "Nanotech may lead to new human health problems" 1.06

Lead to more pollution: "Nanotech may lead to more pollution and environmental contamination" 1.06

Loss of U.S. jobs: "Because of nanotech we may lose more U.S. jobs" 1.850 .98

Spread of tiny robots: "Nanotech may lead to the uncontrollable spread of very tiny self-replicating robots" $1.51 \quad 0.90$

Benefit perceptions

Treating diseases: "Nanotech may lead to new and better ways to treat and detect human diseases" $2.96 \quad 1.06$

Clean environment: "Nanotech may lead to new and better ways to clean up the environment" 2.81

Improve human abilities: "Nanotech may give scientists the ability to improve human physical and mental abilities" $2.69 \quad 1.21$

Improve national security: "Nanotech may help us develop increased national security and defensive capabilities" $2.62 \quad 1.06$

Solve energy problems: "Nanotech may lead to technologies that will help solve our energy problems" $2.27 \quad 1.16$

Revolutionize computer industry: "Nanotech may revolutionize the computer industry" 1.850 .98

Lead to economic boom: "Nanotech may lead to a new economic boom"

Table 3 Summary statistics for adequacy of existing nanotechnology regulations

Thinking about applications of nanotechnology in each of the following areas, please indicate to which degree you think current regulations are sufficient or we need new regulations to address the new realities created by nanotechnology

\begin{tabular}{llrrrr}
\hline & $\begin{array}{l}1=\text { Current regulations } \\
\text { are sufficient }(\%)\end{array}$ & $2(\%)$ & $3(\%)$ & $\begin{array}{c}4(\%) \\
5=\text { We need new } \\
\text { regulations }(\%)\end{array}$ \\
\hline Surveillance and privacy & 14.4 & 13.2 & 27.3 & 19.5 & 25.5 \\
Biological engineering/human enhancement & 12.5 & 9.7 & 23.1 & 31.6 & 23.1 \\
Medical field & 14.5 & 13.3 & 27.1 & 27.4 & 17.8 \\
Environment and energy & 17.2 & 13.6 & 29.8 & 22.9 & 16.6 \\
Military and defense & 19.1 & 13.7 & 29.5 & 21.6 & 16.1 \\
Cosmetics & 17.9 & 16.7 & 25.5 & 24.0 & 15.8 \\
Machines and computers & 35.1 & 20.1 & 27.9 & 9.9 & 6.9 \\
\hline
\end{tabular}

and political/social values. In order to do this, we ran a hierarchical OLS regression model with three blocks of variables. The first block was a set of demographic variables that included gender, disciplinary field, and political/social values. The second block included a general measure for nanotechnology risk perceptions and a general measure for nanotechnology benefit perceptions. The third block included specific application areas for nanotechnology risk and benefit perceptions. The dependent variable for our analysis was the summative index of two statements: (1) "Academic nanotechnology research should be 
regulated" $(1=$ Strongly disagree; $5=$ Strongly agree) and (2) "Commercial nanotechnology research should be regulated" ( $1=$ Strongly disagree; $5=$ Strongly agree).

The results for our OLS model are presented in Table 4. The before-entry Betas are presented in Table 4 for each block. The results demonstrate that the demographic variables account for $15.7 \%$ of the variance in the nanoscientists' support for regulation of nanotechnology. We also included control variables for gender and scientific discipline based on their importance in previous research on nanotechnology. Powell (2007) found that the way scientists view nanotechnology risks can depend on the type of research they conduct and their disciplinary fields. Siegrist et al. (2008) found gender differences in the perceived benefits about nanotechnology. The negative coefficient on gender in our model indicates that male scientists were less supportive of regulation than their female peers. We also observed some interesting disciplinary differences for the support of regulation. The materials scientists in the sample were more supportive of regulation than any other discipline in the sample.

An analysis of the political and social ideology variables confirms our third hypothesis. Higher levels of societal allocation of risk were associated with less support for regulation. Therefore, as nanoscientists think that the public should be willing to accept more risks for potential societal benefits, they are less supportive of nanotechnology regulation. We further examined social values by including economic and social conservatism variables in our model. As previously mentioned, several scholars have found that scientists often use normative values when making decisions about risk, just as the public does (Douglas and Wildavsky 1982; Plutzer et al. 1998; Slovic et al. 1995). As Kunreuther and Slovic (1996) and others (Kahan et al. 2008; Renn and Roco 2006) have argued, value choices are unavoidable in the process of forming risk and regulation perspectives. Also, research has shown that people consider economic development opportunities when they think about regulating nanotechnology (Bowman and Hodge 2006). While social conservatism was not significant, economic conservatism was negatively correlated with support for regulation. More economically conservative nanoscientists were less supportive
Table 4 Hierarchical OLS regression analysis for regulation of nanotechnology ${ }^{a}$

Before-entry $\beta$

\begin{tabular}{|c|c|}
\hline \multicolumn{2}{|l|}{ Demographics and values } \\
\hline \multicolumn{2}{|l|}{ Disciplinary fields and gender } \\
\hline Male & $-0.11 *$ \\
\hline Biology & -0.07 \\
\hline Physics & 0.02 \\
\hline Engineering & -0.03 \\
\hline Materials sciences & $0.11^{*}$ \\
\hline Other disciplines & -0.05 \\
\hline \multicolumn{2}{|l|}{ Political/social ideology } \\
\hline Economic conservatism $^{\mathrm{b}}$ & $-0.19 * *$ \\
\hline Social conservatism $^{\mathrm{c}}$ & 0.07 \\
\hline Societal allocation of risk ${ }^{\mathrm{d}}$ & $-0.23 * *$ \\
\hline Incremental $R^{2}$ (in \%) & $15.7 * *$ \\
\hline \multicolumn{2}{|c|}{ Overall perceived risks and benefits } \\
\hline Overall risk perception $^{\mathrm{e}}$ & $0.26^{* *}$ \\
\hline Overall benefit perception ${ }^{\mathrm{f}}$ & 0.04 \\
\hline Incremental $R^{2}$ (in \%) & $6.8 * *$ \\
\hline \multicolumn{2}{|c|}{ Risks and Benefits in Application Areas } \\
\hline \multicolumn{2}{|l|}{ Risk perceptions } \\
\hline Loss of privacy ${ }^{\mathrm{g}}$ & $0.14 * *$ \\
\hline Lead to arms race ${ }^{\mathrm{h}}$ & $0.18 * *$ \\
\hline Lead to health problems ${ }^{\mathrm{i}}$ & $0.17 * *$ \\
\hline Used by terrorists $^{\mathrm{j}}$ & $0.14 * *$ \\
\hline Loss of U.S. jobs ${ }^{\mathrm{k}}$ & 0.07 \\
\hline Spread of tiny robots ${ }^{1}$ & $0.20 * *$ \\
\hline Lead to more pollution ${ }^{\mathrm{m}}$ & $0.12 *$ \\
\hline \multicolumn{2}{|l|}{ Benefit perceptions } \\
\hline Treating diseases ${ }^{\mathrm{n}}$ & $-0.09 * *$ \\
\hline Clean environment $^{\circ}$ & -0.03 \\
\hline Improve human abilities $^{\mathrm{p}}$ & $0.13 *$ \\
\hline Improve national security ${ }^{\mathrm{q}}$ & -0.05 \\
\hline Solve energy problems ${ }^{\mathrm{r}}$ & -0.04 \\
\hline Revolutionize computers ${ }^{\mathrm{s}}$ & -0.06 \\
\hline Lead to economic boom ${ }^{t}$ & 0.04 \\
\hline Incremental $R^{2}$ (in \%) & $9.4 * *$ \\
\hline Total $R^{2}$ (in $\%$ ) & $31.8^{* *}$ \\
\hline
\end{tabular}

Note: $* p<0.05 ; * * p<0.01$

a The dependent variable for the model is the summative index of "Academic nanotechnology research should be regulated" and "Commercial nanotechnology research should be regulated." The response categories for each statement are $1=$ Strongly disagree; $5=$ Strongly agree. (Cronbach's alpha $=0.766$ ) 
Table 4 continued

b "In terms of economic issues, would you say you are: $(1=$ Very liberal; $7=$ Very conservative $)$

c "In terms of social issues, would you say you are: ( 1 = Very liberal; $7=$ Very conservative $)$

d Societal allocation of risk variable is based on the response to the following survey question: "Advancing nanotechnology quickly is more important than protecting society from the unknown risks" ( $1=$ Strongly disagree; $5=$ Strongly agree $)$

e Overall risk perceptions are based on response to the following survey question: "Nanotechnology is risky for society" ( $1=$ Strongly disagree; $5=$ Strongly agree $)$

${ }^{\mathrm{f}}$ Overall benefit perceptions are based on response to the following survey question: "Nanotechnology is useful for society" ( $1=$ Strongly disagree; $5=$ Strongly agree $)$

g Risk perception about Privacy is based on the response to the following survey question: "Nanotech may lead to the loss of personal privacy because of tiny new surveillance devices" ( $1=$ Strongly disagree; $5=$ Strongly agree $)$

h Risk perception about Arms Race is based on the response to the following survey question: "Nanotech may lead to an arms race between the U.S. and other countries" $(1=$ Strongly disagree; $5=$ Strongly agree)

${ }^{\mathrm{i}}$ Risk perception about Human Health is based on the response to the following survey question: "Nanotech may lead to new human health problems" $(1=$ Strongly disagree; $5=$ Strongly agree)

${ }^{\mathrm{j}}$ Risk perception about Terrorists is based on the response to the following survey question: "Nanotech may be used by terrorists against the U.S." $\quad(1=$ Strongly disagree; $5=$ Strongly agree)

${ }^{k}$ Risk perception about Loss of Jobs is based on the response to the following survey question: "Because of nanotech we may lose more U.S. jobs." $(1=$ Strongly disagree; $5=$ Strongly agree)

${ }^{1}$ Risk perception about Tiny Robots is based on the response to the following survey question: "Nanotech may lead to the uncontrollable spread of very tiny self-replicating robots" $(1=$ Strongly disagree; $5=$ Strongly agree $)$

${ }^{m}$ Risk perception about Environment is based on the response to the following survey question: "Nanotech may lead to more pollution and environmental contamination" $(1=$ Strongly disagree; 5 = Strongly agree)

${ }^{n}$ Benefit perception about Treating Diseases is based on the response to the following survey question: "Nanotech may lead to new and better ways to treat and detect human diseases" $(1=$ Strongly disagree; $5=$ Strongly agree $)$

${ }^{o}$ Benefit perception about Clean Environment is based on the response to the following survey question: "Nanotech may lead to new and better ways to clean up the environment" $(1=$ Strongly disagree; $5=$ Strongly agree $)$

p Benefit perception about Improve Human Abilities is based on the response to the following survey question: "Nanotech may give scientists the ability to improve human physical \& mental abilities" ( $1=$ Strongly disagree; $5=$ Strongly agree $)$
Table 4 continued

q Benefit perception about Improve National Security is based on the response to the following survey question: "Nanotech may help us develop increased national security and defensive capabilities" ( $1=$ Strongly disagree; $5=$ Strongly agree)

${ }^{\mathrm{r}}$ Benefit perception about Solve Energy Problems is based on the response to the following survey question: "Nanotech may lead to technologies that will help solve our energy problems" $(1=$ Strongly disagree; $5=$ Strongly agree $)$

s Benefit perception about Revolutionize Computer Industry is based on the response to the following survey question: "Nanotech may revolutionize the computer industry" $(1=$ Strongly disagree; $5=$ Strongly agree $)$

${ }^{t}$ Benefit perception about Lead to Economic Boom is based on the response to the following survey question: "Nanotech may lead to a new economic boom" $(1=$ Strongly disagree; $5=$ Strongly agree)

of nanotechnology regulation. Even though some scientists might argue that they make objective decisions about their areas of expertise, clearly the leading U.S. nanoscientists make policy suggestions about their fields by viewing the issue through their individual economic value frames. Since one of the main reasons for governmental regulation is the existence of market failure, if scientists perceive that the market is the most efficient mechanism for the development of technology, they might be less supportive of regulation.

The second block of variables in our OLS regression included overall risk and benefit perception measures. These two variables explained an additional $6.8 \%$ of the variance in the model. The results demonstrate that our first hypothesis was confirmed for the overall risk perceptions, but our second hypothesis was not confirmed for overall benefit perceptions. As nanoscientists had higher risk perceptions, they were more supportive of nanotechnology regulation. We were surprised to find, however, that benefit perceptions were not significantly correlated with support for nanotechnology. This finding demonstrates that the public and scientists use different heuristics when they are asked to make decisions about nanotechnology. As previously mentioned, Scheufele and Lewenstein (2005) found that the public uses cognitive shortcuts to make policyrelated decisions about nanotechnology because they have little information about the scientific details. In addition, they argued that these cognitive shortcuts are often provided by the way the media portrays the 
issue of nanotechnology (i.e., media framing) since media coverage of nanotechnology in the USA has been largely focused on the potential benefits of the field rather than the potential risks (Gaskell et al. 2004). Thus, Scheufele and Lewenstein (2005) found that the public used benefit perceptions, but not risk perceptions, when making decisions about nanotechnology. Our results for the nanoscientists are in contrast to the earlier results for the public's heuristics, with nanoscientists relying on their risk perceptions but not benefit perceptions. We speculate that the nanoscientists might view regulations as protections for the public (and therefore focus on the potential risks), while the public might think of regulations as restricting their access to nanotechnology benefits (and therefore focus on the potential benefits). Clearly, these are contrasting ways of thinking about nanotechnology and its potential benefits and risks.

The third block of our OLS regression model included a series of risk perception variables and benefit perception variables for specific nanotechnology application areas. These variables explained an additional $9.4 \%$ of the variance in the nanoscientists' support for regulation. The results for the risk perceptions further confirmed our first hypothesis. Risk perceptions for all nanotechnology application areas except one (loss of U.S. jobs) were significantly - and positively — correlated with support for nanotechnology regulation. Thus, as perceptions of risk increased for privacy, defense, human health, terrorists, tiny robots, and environment, nanoscientists' support for regulation increased. The standardized coefficients show that the two risk application areas that had the strongest relationship with support for regulation were defense and human health.

The results for the benefit perceptions were similar to those for the previous block with only two benefit perceptions being significantly correlated with support for regulation: treating diseases and improving human abilities. As the nanoscientists perceived higher benefits for treating diseases, they were less supportive of nanotechnology regulation. The relationship for the benefit of improving human abilities was in the opposite direction. As the nanoscientists perceived more nanotech benefits related to improving human abilities, they were more supportive of nanotechnology regulations. We speculate that this result, combined with the above result about risks related to human health, means that the nanoscientists are particularly concerned about how nanotechnology will impact human health. While they were concerned about risks related to human health and this led to more support for regulation, they are also concerned about benefits related to improving human abilities. We speculate that this is because the nanoscientists are not sure that the benefits related to improving human abilities will be held in check without governmental regulations. Therefore, while they see this as a potentially beneficial area, they are concerned about how those benefits might play out in the absence of stricter regulations. Thus, as they perceive higher potential benefits, they are more supportive of having regulations in place that could limit accompanying negative impacts on human health.

In addition to testing our three formal hypotheses, we found some other noteworthy results. First, the summary statistics for the regulation variables in Table 2 demonstrate that the scientists were slightly more supportive of regulating commercial nanotechnology than they were for regulating academic nanotechnology. Perhaps this is related to the fact that commercial nanotechnology research is often directly related to product development and the use of nanotechnology by consumers. Second, nanoscientists were most supportive of national level nanotechnology regulations, with the international level coming in second (see Table 2). This is another interesting finding because recent study by Scheufele et al. (2009) demonstrates that people in different countries have different perceptions about the moral acceptability of nanotechnology. Therefore, it is quite possible that national level policies could differ significantly across countries (Marchant and Sylvester 2006; Tyshenko and Krewski 2008). If a nanotechnology regulatory framework is adopted that is not internationally implemented, then companies might simply move their products and research to countries with less stringent regulations.

\section{Conclusions}

Our data provide the first nationally generalizable assessment of attitudes and regulatory views among leading U.S. nanoscientists. As we outlined earlier, systematic feedback from scientists similar to the one 
provided in our study is absolutely critical during policy debates that are characterized by a noticeable absence of conclusive evidence on the concrete risks connected with emerging technologies. Toward that end, our results provide a number of concrete pieces of advice for policy makers who are planning to use input from nanoscientists in their plans for nanotechnology regulation.

The first policy implication from our data is that the leading U.S. nanoscientists believe that we most urgently need new regulations in the areas of surveillance/privacy, human enhancement, medicine, and the environment. Instead of focusing time and energy on new regulations in other areas where nanoscientists would argue that current regulations are largely sufficient (like machines and computers), policy-makers should focus their policy development efforts on these higher priority areas. This finding is particularly relevant, given the current piecemeal nature of the regulatory framework for nanotech. As resources and time constraints make the formation of new nanotechnology policies increasingly difficult, policy-makers should focus first on regulating the areas where leading nanoscientists see the highest risk and the most need for regulation.

The second implication is related to the differences in the way scientists and the public make policy decisions about nanotechnology. Even though we do not compare scientist and public survey data in this research, we have discussed a similar study that focused on the heuristics that the public uses when discussing nanotechnology (Scheufele and Lewenstein 2005). We can utilize these earlier results to draw some conclusions about the way the public thinks about nanotechnology policy decisions, and to compare them with our findings about how scientists make policy decisions about nanotechnology. Scheufele and Lewenstein (2005) found that the public tends to rely on their perceived benefits (rather than perceived risks) when making decisions about nanotechnology. Yet, in this study, we found that nanoscientists tend to make decisions about the need for nanotechnology regulation based on perceived risks and political/economic values. This distinction could be important for policy-makers if they are planning to include both nanoscientists and the public in the policy-making process. Clearly, the public and scientists rely on different cognitive shortcuts when they think about the regulation of nanotechnology.
Third, our findings highlight the importance of developing a systematic understanding of the demographic antecedents among policy perceptions for nanoscientists. In particular, our analyses show that economic conservatism among scientists was related to less support for regulation, and that more economically liberal scientists - in turn-were more likely to support regulations. The fact that views on regulation among the leading U.S. nanoscientists is driven by personal ideologies-even after also controlling for their scientific judgment about potential risks and benefits-may be troublesome to some observers, especially since journalists and policymakers alike routinely turn to experts from the research community when they need information on nanoscience and regulation.

Finally, since nanoscientists' support for nanotechnology regulation is significantly related to their risk perceptions, it will be important for policymakers to continually include scientists in their decision-making processes about developing new (and refining old) policies for nanotechnology. We speculate that as additional risk assessment data become available—and, therefore, as nanoscientists' perceptions about the risks of nanotech evolve-their support for the regulation of nanotechnology will also change. Policy-makers should not assume that nanoscientists have a static view of the regulation of their field. Thus, a long-term regulatory framework for nanotechnology should allow for scientists' changing risk perceptions, the public's changing benefit perceptions, as well as updated rational risk assessment data as it becomes available over time.

Acknowledgments This material is based on work supported by grants from the National Science Foundation (SES0531194) and the University of Wisconsin-Madison Graduate School (135GL82). Any opinions, findings, and conclusions or recommendations expressed in this material are those of the authors and do not necessarily reflect the views of the NSF or the UW-Madison Graduate School.

\section{References}

Bennett I, Sarewitz D (2006) Too little, too late? Research policies on the societal implications of nanotechnology in the United States. Sci Cult 15(4):309-325

Berube DM (2008) Rhetorical gamesmanship in the nano debates over sunscreens and nanoparticles. J Nanopart Res 10:23-37. doi:10.1007/s11051-008-9362-7

Besley J, Kramer V, Priest S (2008) Expert opinion on nanotechnology: risks, benefits, and regulation. J Nanopart Res 10(4):549-558. doi:10.1007/s11051-007-9323-6 
Bowman DM, Hodge GA (2006) Nanotechnology: mapping the wild regulatory frontier. Futures 38(9):1060-1073. doi:10.1016/j.futures.2006.02.017

Carr S, Levidow L (2000) Exploring the links between science, risk, uncertainty, and ethics in regulatory controversies about genetically modified crops. J Agric Environ Ethics 12(1):29-39. doi:10.1023/A:1009595924500

Chau CF, Wu SH, Yen GC (2007) The development of regulations for food nanotechnology. Trends Food Sci Technol 18(5):269-280. doi:10.1016/j.tifs.2007.01.007

Cobb MD, Macoubrie J (2004) Public perceptions about nanotechnology: risks, benefits and trust. J Nanopart Res 6(4):395-405. doi:10.1007/s11051-004-3394-4

Dillman DA, Smyth JD, Christian LM (2008) Internet, mail, and mixed-mode surveys: the tailored design method. Wiley, New York

Douglas M, Wildavsky A (1982) Risk and culture. University of California Press, Berkeley, CA

European Food Safety Authority (2009) Scientific opinion: the potential risks arising from nanoscience and nanotechnologies on food and feed safety. EFSA J 958:1-39

Faunce TA (2007) Nanotherapeutics: new challenges for safety and cost-effectiveness regulation in Australia. Med J Aust 186(4):189-191

FDA (2009) FDA and nanotechnology products. http://www. fda.gov/nanotechnology/faqs.html. Accessed 13 May 2009

Fisher E (2007) The convergence of nanotechnology, policy, and ethics. Adv Comput 71:273-296

Franco A, Hansen SF, Olsen SI, Butti L (2007) Limits and prospects of the "incremental approach" and the European legislation on the management of risks related to nanomaterials. Regul Toxicol Pharmacol 48(2):171-183. doi:10.1016/j.yrtph.2007.03.007

Frank RH (1988) Passions within reason: the strategic role of the emotions. W.W. Norton, New York

Friedman SM, Egolf BP (2005) Nanotechnology: risks and the media. IEEE Technol Soc Mag 24:5-11. doi:10.1109/ MTAS.2005.1563496

Friedrichs S, Schulte J (2007) Environmental, health and safety aspects of nanotechnology-implications for the R\&D in (small) companies. Sci Technol Adv Mater 8:12-18. doi: 10.1016/j.stam.2006.11.020

Gaskell G, Ten Eyck TA, Jackson J, Veltri G (2004) Public attitudes to nanotechnology in Europe and the United States. Nat Mater 3(8):496. doi:10.1038/nmat1181

Gewin V (2006) Nanotech's big issue. Nature 443(7108):137. doi:10.1038/nj7108-242a

Iyengar S (1991) Is anyone responsible? How television frames political issues. University of Chicago Press, Chicago, IL

Jasanoff S (1990) The fifth branch: science advisers as policymakers. Harvard University Press, Cambridge, MA

Kahan DM, Slovic P, Braman D, Gastil J, Cohen G, Kysar D (2008) Biased assimilation, polarization, and cultural credibility: an experimental study of nanotechnology risk perceptions. Project on Emerging Nanotechnologies Research Brief No. 3

Kunreuther H, Slovic P (1996) Science, value, and risk. Ann Am Acad Political Soc Sci 545(1):116-125. doi:10.1177/ 0002716296545001012
Kuzma J (2007) Moving forward responsibly: oversight for the nanotechnology-biology interface. J Nanopart Res 9(1): 165-182. doi:10.1007/s11051-006-9151-0

Kuzma J, Paradise J, Ramachandran G, Kim JA, Kokotovich A, Wolf SM (2008) An integrated approach to oversight assessment for emerging technologies. Risk Anal 28(5): 1197-1219. doi:10.1111/j.1539-6924.2008.01086.x

Lee R, Jose D (2008) Self-interest, self-restraint and corporate responsibility for nanotechnologies: emerging dilemmas for modern managers. Technol Anal Strateg Manag 20(1):113-125. doi:10.1080/09537320701726775

Magnus D (1997) Heuristics and biases in evolutionary biology. Biol Philos 12(1):21-38. doi:10.1023/A:1017953510082

Marchant GE, Sylvester DJ (2006) Transnational models for regulation of nanotechnology. J Law Med Ethics 34(4): 714-725. doi:10.1111/j.1748-720X.2006.00091.x

McGarity TO (1978-1979) Substantive and procedural discretion in administration resolution of science policy questions: regulating carcinogens in EPA and OSHA. Georget Law J 67: 729-809

O'Brien N, Cummins E (2008) Recent developments in nanotechnology and risk assessment strategies for addressing public and environmental health concerns. Hum Ecol Risk Assess 14(3):568-592. doi:10.1080/10807030802074261

Plutzer E, Maney A, O'Connor RE (1998) Ideology and elites' perceptions of the safety of new technologies. Am J Pol Sci 42(1):190-209. doi:10.2307/2991752

Porter AL, Youtie J, Shapira P, Schoeneck DJ (2008) Refining search terms for nanotechnology. J Nanopart Res 10(5): 715-728. doi:10.1007/s11051-007-9266-y

Powell MC (2007) New risk or old risk, high risk or no risk? How scientists' standpoints shape their nanotechnology risk frames. Health Risk Soc 9(2):173-190. doi:10.1080/ 13698570701306872

Powell M, Griffin MPA, Tai S (2008) Bottom-up risk regulation? How nanotechnology risk knowledge gaps challenge federal and state environmental agencies. Environ Manag 42(3):426-443. doi:10.1007/s00267-008-9129-z

Reinert K, Andrews L, Keenan R (2006) Nanotechnology nexus-intersection of research, science, technology, and regulation. Hum Ecol Risk Assess 12(5):811-818. doi: 10.1080/10807030600848601

Renn O, Roco M (2006) Nanotechnology and the need for risk governance. J Nanopart Res 8(2):153-191. doi:10.1007/ s11051-006-9092-7

Revkin A (2004, October 19) Bush vs. The laureates: how science became a Partisan issue. New York Times

Rickerby DG (2007) Nanotechnological medical devices and nanopharmaceuticals: the European regulatory framework and research needs. J Nanosci Nanotechnol 7(12):4618-4625

Salter L, Levy E, Leiss W (1988) Mandated science: science and scientists in the making of standards. Kluwer Academic Publishers, Boston, MA

Samarapungavan A, Westby EL, Bodner GM (2006) Contextual epistemic development in science: a comparison of chemistry students and research chemists. Sci Educ 90(3): 468-495. doi:10.1002/sce.20111

Scheufele DA (2006) Messages and heuristics: how audiences form attitudes about emerging technologies. In: Turney $\mathbf{J}$ (ed) Engaging science: thoughts, deeds, analysis and action. The Wellcome Trust, London, pp 20-25 
Scheufele DA, Lewenstein BV (2005) The public and nanotechnology: how citizens make sense of emerging technologies. $\mathrm{J}$ Nanopart Res 7(6):659-667. doi:10.1007/s11051-005-75 26-2

Scheufele DA, Corley EA, Dunwoody S, Shih T-J, Hillback E, Guston DH (2007) Scientists worry about some risks more than the public. Nat Nanotechnol 2(12):732-734. doi: 10.1038/nnano.2007.392

Scheufele DA, Corley EA, Shih T-j, Dalrymple KE, Ho SS (2009) Religious beliefs and public attitudes toward nanotechnology in Europe and the United States. Nat Nanotechnol 4(2):91-94. doi:10.1038/nnano.2008.361

Schummer J, Baird D (2006) Nanotechnology challenges: implications for philosophy, ethics and society. World Scientific Publishing, Hackensack, NJ

Siegrist M, Cousin M-E, Kastenholz H, Wiek A (2007a) Public acceptance of nanotechnology foods and food packaging: the influence of affect and trust. Appetite 49:459-466

Siegrist M, Keller C, Kastenholz H, Frey S, Wiek A (2007b) Laypeople's and experts' perception of nanotechnology hazards. Risk Anal 27(1):59-69. doi:10.1111/j.15396924.2006.00859.x
Siegrist M, Stampfli N, Kastenholz H, Keller C (2008) Perceived risks and perceived benefits of different nanotechnology foods and nanotechnology food packaging. Appetite 51(2):283-290. doi:10.1016/j.appet.2008.02.020

Silva CL, Jenkins-Smith HC (2007) The precautionary principle in context: U.S. and E.U. scientists' prescriptions for policy in the face of uncertainty. Soc Sci Q 88(3):640664. doi:10.1111/j.1540-6237.2007.00476.x

Slovic P, Malmfors T, Krewski D, Mertz CK, Neil N, Bartlett S (1995) Intuitive toxicology II: expert and lay judgments of chemical risks in Canada. Risk Anal 15(6):661-675. doi: 10.1111/j.1539-6924.1995.tb01338.x

Sniderman PM, Brody RA, Tetlock PE (1991) Reasoning and choice: explorations in political psychology. Cambridge University Press, New York

Sunstein CR (2005) Moral heuristics. Behav Brain Sci 28(4): 531-573

Tyshenko MG, Krewski D (2008) A risk management framework for the regulation of nanomaterials. Int $\mathrm{J}$ Nanotechnol 5(1):143-160. doi:10.1504/IJNT.2008.016553

Zaller JR (1992) The nature and origins of mass opinion. Cambridge University Press, New York 